\title{
Scheie syndrome
}

INSERM

\section{Source}

INSERM. (1999). Orphanet: an online rare disease and orphan drug data base. Scheie syndrome. ORPHA:93474

Scheie syndrome is the mildest form of mucopolysaccharidosis type 1 (MPS1; see this term), a rare lysosomal storage disease, characterized by skeletal deformities and a delay in motor development. 